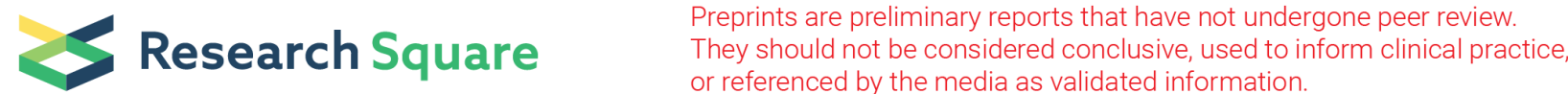

\section{Application of Pier Waste Sludge for Catalytic Activation of Proxy-monosulfate and Phenol Elimination From a Petrochemical Wastewater}

\section{Feyzollah Khoshtinat}

Islamic Azad University Bushehr Branch

Tayebeh Tabatabaie

Islamic Azad University Bushehr Branch

Bahman Ramavandi ( $\sim$ ramavandi_b@yahoo.com )

Bushehr University of Medical Sciences https://orcid.org/0000-0002-4823-2113

Seyedenayat Hashemi

Bushehr University of Medical Sciences

\section{Research Article}

Keywords: Waste sludge, Phenol, Petrochemical wastewater, Kinetic, Energy consumption

Posted Date: December 30th, 2021

DOI: https://doi.org/10.21203/rs.3.rs-1058607/v1

License: (c) (i) This work is licensed under a Creative Commons Attribution 4.0 International License. Read Full License 


\section{Abstract}

This investigation aimed to remove phenol from a real wastewater (taken from a petrochemical company) by activating peroxy-monosulfate (PMS) using catalysts extracted from pier waste sludge. The physical and chemical properties of the catalyst were evaluated by FE-SEM/EDS, XRD, FTIR, and TGA/DTG tests. The functional groups of $\mathrm{O}-\mathrm{H}, \mathrm{C}-\mathrm{H}, \mathrm{CO}_{3}{ }^{2-}, \mathrm{C}-\mathrm{H}, \mathrm{C}-\mathrm{O}, \mathrm{N}-\mathrm{H}$, and $\mathrm{C}-\mathrm{N}$ were identified on the catalyst surface. Also, the crystallinity of the catalyst before and after reaction with petrochemical wastewater was $103.4 \mathrm{~nm}$ and $55.8 \mathrm{~nm}$, respectively. Operational parameters of $\mathrm{pH}(3-9)$, catalyst dose (0-100 mg/L), phenol concentration (50-250 mg/L), and PMS concentration (0-250 mg/L) were tested to remove phenol. The highest phenol removal rate $(94 \%)$ was obtained at $\mathrm{pH}=3$, catalyst dose of $80 \mathrm{mg} / \mathrm{L}$, phenol concentration of $50 \mathrm{mg} / \mathrm{L}$, PMS concentration of $150 \mathrm{mg} / \mathrm{L}$, and contact time of $150 \mathrm{~min}$. Phenol decomposition in petrochemical wastewater followed the first-order kinetics $\left(k>0.008 \mathrm{~min}^{-1}, R^{2}>0.94\right)$. Based on the reported results, it was found that the $\mathrm{pH}$ factor is more important than other factors in phenol removal. The catalyst stability test was performed for up to five cycles and phenol removal in the fifth cycle was reduced to $42 \%$. Also, the energy consumption in this study was $77.69 \mathrm{kw} . \mathrm{h} / \mathrm{m}^{3}$. According to the results, the pier waste sludge catalyst/PMS system is a critical process for eliminating phenol from petrochemical wastewater.

\section{Introduction}

Wastewater from various industries, including oil refineries, coke, paper, textiles, and petrochemical industries, contains phenol and its derivatives (Ganguly et al. 2020). Phenolic compounds are chemically stable and soluble in water (Honarmandrad et al. 2021, Othman et al. 2020). These compounds pose very serious risks to human health and the environment, so they must be properly disposed before discharge into the environment (Honarmandrad et al. 2021, Mady et al. 2019). Drinking phenol-containing water can disrupt the sleep system, damage the kidneys and pancreas, damage the central nervous system, and possibly cause cancer in humans (Al Bsoul et al. 2021). Given the importance of phenol on human health and the environment, the US Environmental Protection Agency has set a maximum concentration of phenol in industrial effluents for discharge to surface water sources of $1 \mathrm{mg} / \mathrm{L}$ (Ganguly et al. 2020, Othman et al. 2020).

Various methods are used to remove phenol from wastewater, including adsorption (Nirmala et al. 2021), ion exchange (Camacho et al. 2021), membrane processes (Ali et al. 2021), reverse osmosis (Al-Huwaidi et al. 2021), and biological processes (Pandian et al. 2021). Conventional treatment methods, however, face challenges such as inefficiency at high phenol concentrations, management and disposal of saturated adsorbents, high cost, and long process times (Bin-Dahman \&Saleh 2020).

Sulfate radical-based advanced oxidation processes (AOPs) with the production of free radicals with high oxidation strength (2.5-3.1 eV) (Khan et al. 2017), longer half-life (30-40 $\mu$ s) (Cui et al. 2017, Wang et al. 2019) and its effect on a wider $\mathrm{pH}$ range (2-8) as an effective and efficient method, can convert organic chemical compounds into minerals (Eslami et al. 2018, Li et al. 2021). 
$\mathrm{HSO}_{5}^{-} \rightarrow \mathrm{SO}_{4}^{--}+\mathrm{OH}^{-}$

$\mathrm{HSO}_{5}^{-} \rightarrow \mathrm{SO}_{5}^{--}+\mathrm{H}^{+}$

$\mathrm{SO}_{4}{ }^{--}+\mathrm{H}_{2} \mathrm{O} \rightarrow \mathrm{SO}_{4}{ }^{2-}+\cdot \mathrm{OH}+\mathrm{H}^{+}$

$\mathrm{C}_{6} \mathrm{H}_{5} \mathrm{OH}+\cdot \cdot \mathrm{OH} / \mathrm{SO}_{4}^{--} \rightarrow$ Reaction products $\rightarrow \mathrm{CO}_{2}+\mathrm{H}_{2} \mathrm{O}$

Removal of phenol using PMS activation by $\mathrm{CuFe} / 2 / \mathrm{MnO}_{2}$ catalysts (Liu et al. 2021), $\mathrm{CoO} @ \mathrm{TiO}_{2} / \mathrm{MXene}$ (Ding et al. 2021), $\mathrm{\gamma}-\mathrm{Fe}_{2} \mathrm{O}_{3} / \mathrm{MnO}_{2}$ (Wang et al. 2021), $\mathrm{CeVO}_{4}$ (Othman et al. 2020), $\mathrm{Co}_{3} \mathrm{O}_{4}-\mathrm{Bi}_{2} \mathrm{O}_{3}$ (Hu et al. 2019), and $\mathrm{CeO}_{2}$ (Gao et al. 2021) have been performed in previous studies. However, due to the secondary contamination, high cost, and inefficiency of these catalysts, researchers are seeking to obtain inexpensive, high-performance, environmentally friendly catalysts (Zhang et al. 2020). Therefore, in this study, the pier waste sludge was used for the first time as a catalyst to remove phenol from a petrochemical wastewater. Extensive studies have been performed on the removal of phenol from synthetic wastewater by PMS systems. The challenge facing this system is its efficiency in removing phenol from real wastewater. Studies in this area are rare. Thus, the aim of this study is to remove phenol from petrochemical wastewater by pier waste sludge/PMS system. The effect of various operating parameters such as solution $\mathrm{pH}$, catalyst dose, phenol concentration, PMS concentration, and reaction time were also investigated. In this study, the physical and chemical properties of the prepared catalyst before and after the reaction with real wastewater and the stability and reuse of the catalyst were presented.

\section{Materials And Methods}

\subsection{Chemicals}

Phenol $\left(\mathrm{C}_{6} \mathrm{H}_{5} \mathrm{OH}\right)$ with $99 \%$ purity, $\mathrm{NaOH}$, and $\mathrm{HCl} 0.1 \mathrm{M}$ was prepared from Kimia Material Company, Iran. Potassium peroxy-monosulfate $\left(2 \mathrm{KHSO}_{5} \cdot \mathrm{KHSO}_{4} \cdot \mathrm{K}_{2} \mathrm{SO}_{4}\right)$ was purchased from Merck, Germany. Deionized water has been used to prepare a catalyst from pier waste sludge.

\subsection{Catalyst preparation}

The pier waste sludge as a catalytic precursor was collected from Jofreh shipping, Bushehr port, Iran ( $28^{\circ}$ $58^{\prime} 20^{\prime \prime} \mathrm{N}, 50^{\circ} 49^{\prime} 31^{\prime \prime} \mathrm{E}$ ). The pier waste sludge was removed from the tides and in conditions where the seawater was tidal. The pier waste sludge was placed in the oven at $105^{\circ} \mathrm{C}$ for $24 \mathrm{~h}$ to dry. It was then ground and passed through a sieve with mesh number\# 40 to produce uniform particles. The pier waste sludge in the electric furnace was optimized at $400{ }^{\circ} \mathrm{C}$ and the residence time in the furnace for 3 h (Khoshtinat et al. 2021).

\subsection{Real wastewater}


The actual wastewater of this study was prepared from a petrochemical company in Bandar Mahshahr, Iran. Approximately 15 liters of wastewater were taken from the outlet of the equalization pond of the petrochemical wastewater treatment plant. The sample was transferred to the laboratory in sealed containers at intervals of $5 \mathrm{~h}$. The chemical properties of petrochemical wastewater are given in Table S1, which shows the presence of phenol, organic compounds, and salt in it, which are capable to consume $\mathrm{SO}_{4}{ }^{-{ }^{-}}$radicals. According to the range of parameters in petrochemical wastewater and in order to evaluate the efficiency of pier waste sludge catalyst/PMS system on phenol removal efficiency, pHs and initial phenol concentration of the petrochemical wastewater were set in the range of ' $3,5,7,8,9$ ' and '50, 100, 150, 200, $250 \mathrm{mg} / \mathrm{L}$ ', respectively.

\subsection{Design of experiments}

The exact amount of $0.1 \mathrm{~g}$ of phenol was dissolved in $100 \mathrm{~mL}$ of deionized water to obtain a stock solution of $1000 \mathrm{mg} / \mathrm{L}$. This solution was prepared daily to add to the actual wastewater and spiking the phenol concentration to the desired value. All oxidation tests were performed at ambient temperature in batch mode in $250 \mathrm{~mL}$ Erlenmeyer flakes containing $100 \mathrm{~mL}$ of wastewater. All experiments were done in a shaker-incubator (Kimia Novin Company, Iran) at a speed of $200 \mathrm{rpm}$. Operating factors and their range include phenol concentration $(50,100,150,200,250 \mathrm{mg} / \mathrm{L})$, catalyst dose $(0,5,10,20,30,50,80,100$ $\mathrm{mg} / \mathrm{L}), \mathrm{pH}(3,5,7,8,9)$, PMS concentration $(0,50,100,150,200,250 \mathrm{mg} / \mathrm{L})$, and contact time $(20,40,60$, $100,150 \mathrm{~min})$. The effect of $\mathrm{pH}(3,5,7,8,9)$ was tested under constant conditions of contaminant concentration of $100 \mathrm{mg} / \mathrm{L}$, catalyst dose of $30 \mathrm{mg} / \mathrm{L}$, and PMS concentration of $100 \mathrm{mg} / \mathrm{L}$, and the highest removal efficiency was selected as the optimal value. After optimizing the $\mathrm{pH}$, the effect of catalyst dose (0-100 mg/L) was explored under conditions of initial phenol concentration of $100 \mathrm{mg} / \mathrm{L}$, PMS concentration of $100 \mathrm{mg} / \mathrm{L}$, and $\mathrm{pH}=3$ (optimal value obtained from the previous step).

Contaminant dose (50-250 mg/L) was evaluated at PMS concentration of $100 \mathrm{mg} / \mathrm{L}, \mathrm{pH}=3$, and catalyst dose of $80 \mathrm{mg} / \mathrm{L}$. The effect of PMS concentration (0-250 mg/L) was tested under constant conditions of initial phenol content of $100 \mathrm{mg} / \mathrm{L}, \mathrm{pH}=3$, and catalyst dose of $80 \mathrm{mg} / \mathrm{L}$, and the maximum removal efficiency was selected as the optimal PMS concentration. After the specified time, the reaction mixture was filtered through Whatman 42 filter paper. After determining the optimal conditions for phenol removal from petrochemical wastewater, the pollutant removal kinetics was obtained under optimal conditions. The first-order model was used to investigate the kinetic behavior of phenol removal:

$$
\operatorname{Ln} \frac{[\text { final phenol conc. }]}{[\text { initial phenol conc. }]}=-\mathrm{k} . \mathrm{t}
$$

If the graph $\mathrm{Ln} \mathrm{C} / \mathrm{C}_{0}$ against time $\mathrm{t}$ is plotted, a line is obtained, which slope is equal to the reaction rate constant $\left(k, \min ^{-1}\right)$.

In this study, the experiments were repeated three times, and the removal efficiency of phenol (\%) from petrochemical wastewater was calculated by the following equation. 
Removal efficiency $(\%)=\left(\frac{\text { Initial phenol }- \text { Final phenol }}{\text { Initial phenol }}\right) \times 100$

The test of catalyst reutilization for phenol removal from the wastewater was performed under optimal conditions. After filtering the reaction mixture, the separated catalyst particles were washed with distilled water and dried at $105^{\circ} \mathrm{C}$, and used in the next cycle.

\subsection{Measurements}

METTLER TOLEDO pH meter from Switzerland was used to measure $\mathrm{pH}$. Phenol was measured by highperformance liquid chromatography (HPLC) by the AZURA model made by KNAUER Germany. FE-SEM image analysis was performed to investigate the morphology of catalyst particles (pier waste sludge) using the electron microscope scanning device (ZEISS, Sigma VP model). Also, the elemental analysis and chemical composition of the samples were evaluated by X-ray diffraction (XRD) spectroscopy test using Oxford Instruments. XRD patterns were recorded using a detector on an advanced XRD broker with CuKa for crystal structure characterization by 'X Pert Pro, Panalytical, made in the Netherlands at $40 \mathrm{kV}$ and $40 \mathrm{~mA}$ from 5 to $80(2 \theta)$. Functional groups were analyzed using the Fourier Transfer Infrared (FTIR) spectrum, Perkin Elmer Company, made in the USA in the range of $400-4000 \mathrm{~cm}^{-1}$. The TGA device STA 1500 model, Rheometric Scientific Company, made in the USA was applied to investigate the temperature changes of the catalyst samples in the ambient temperature range up to $800^{\circ} \mathrm{C}$.

\section{Results And Discussion}

\subsection{Catalyst characteristics}

\subsubsection{FE-SEM/EDX}

To study the surface morphology of pier waste sludge catalyst particles before and after removal of phenol from petrochemical wastewater, FE-SEM test and also for elemental analysis of these particles, EDX test and elemental analysis map was used. The results of these tests are shown in Fig. S1 and S2. According to Fig. S1, pier waste sludge particles with irregular morphology and an average particle size of about $56 \mathrm{~nm}$ can be seen. Significant amounts of chlorine, sodium, calcium, oxygen, carbon, and magnesium was observed in the results of the EDX test and elemental analysis map of this sample (Kanimozhi et al. 2014). In the microscopic images shown in Fig. S2 of the pier waste sludge sample, after removing the phenol from the petrochemical wastewater, the morphological change compared to the fresh sample is quite evident. According to this image, the particles of pier waste sludge are completely adhered to each other and have created porous pellets with a diameter of about 3-8 $\mu \mathrm{m}$. Also, with increasing magnification, it is clear that the size of nanoparticles in seawater has increased due to agglomeration and the average particle size is about $109 \mathrm{~nm}$, which shows an increase of about twice compared to the pristine sample. In fact, due to the presence of various compounds in petrochemical wastewater in addition to phenol, the adsorption of these compounds on the surface 
of pier waste sludge has caused adhesion between the particles and clumps shown in Fig. S2 (a and b) (Mahieux et al. 2010). In the results of elemental analysis of this sample, carbon concentration has increased significantly and has accounted for more than $80 \%$ of all elements in the system, which confirms the presence of carbon-containing compounds (including phenol) on the surface of pier waste sludge particles. After the mentioned element, the elements of oxygen, chlorine, titanium, and sulfur had the highest concentration among other elements in this system. Significant sulfur concentrations in this sample can be due to the presence of PMS in the solution or to sulfur compounds in petrochemical wastewater (Rivas et al. 2012). Also, due to the relatively acidic environment of the wastewater, some calcium carbonate is probably dissolved in the solution, and therefore the amount of calcium in this sample is less than the previous sample.

\subsubsection{XRD}

For a more detailed study of the crystal phases in these two samples, an XRD test was performed on them and the results are shown in Fig. 1. According to the diffraction pattern of the pier waste sludge sample and by applying it to the reference diffraction patterns, it is clear that the composition of calcium carbonate $\left(\mathrm{CaCO}_{3}\right)$ in two phases of calcite (with trigonal crystal structure and reference code JCPDS 17-14743) and vaterite (with hexagonal crystal structure and code JCPDS reference 13-192) are the major crystalline phases in this sample. The presence of calcium carbonate in the structure of pier waste sludge has already been proven by Tavasol et al. (2020). Also, magnesium oxide (with reference code JCPDS 89-7746) is another phase that can be identified in the sample, the presence of which was predictable due to the significant percentage of magnesium in the elemental analysis results. In the X-ray diffraction pattern related to pier waste sludge after removal of phenol from petrochemical wastewater, it is clear that significant changes have been made in the resulting spectrum. The most important change in this sample is the removal of most of the calcium carbonate-based phases, which was previously observed in the results of elemental analysis. In fact, by placing seawater in a relatively acidic solution of petrochemical wastewater, calcium carbonate phases are dissolved and phases with more chemical stability such as titanium oxide, magnesium oxide, and iron oxide phases remain. The remaining titanium oxide $\left(\mathrm{TiO}_{2}\right)$ in the two phases of anatase (with reference code JCPDS 21-1272) and rutile (with reference code JCPDS 21-1276) both have a tetragonal crystal structure and their differences in how the singlecrystal units are placed next to each other. Also, iron oxide with $\mathrm{Fe}_{2} \mathrm{O}_{3}$ structure, which is known as hematite phase, has been observed in this diffraction pattern (with reference code: JCPDS 86-055), which can be justified due to the presence of iron element in the results of elemental analysis test related to this sample. Another parameter that can be measured by XRD is the size of the crystals in the crystalline materials. The Scherer equation (Eq. (7)) is used to calculate the crystal size (Hajipour et al. 2021).

$$
\mathrm{D}=\mathrm{K} \lambda / \mathrm{B} \cos (\theta)
$$

In this equation, $\lambda$ is the $X$-ray wavelength used (here $1.54 \AA$ ), $K$ is the shape factor $(\approx 0.9), B$ is the peak width at half of the height and $\theta$ is the peak location. 
By calculating the crystallite size of calcite in the catalyst sample before phenol removal and also titanium oxide in the catalyst after phenol removal by this relation, this value for these two samples is equal to 103.4 and $55.8 \mathrm{~nm}$, respectively. From this decrease in crystal size, it can be concluded that the deposition of phenol in the solution on the catalyst during the removal process has reduced the degree of system crystallinity and therefore the crystal range of the grains in the presence of the amorphous phase of phenol has decreased.

\subsubsection{FTIR}

In order to more accurately study the chemical structure of the compounds in the fresh and used catalysts, the FTIR test was used and the results are shown in Fig. S3. In Fig. S3, the broad peak located at $3438 \mathrm{~cm}^{-1}$ wavelength corresponds to the $0-\mathrm{H}$ bonds in adsorbed water or other hydroxyl groups (Sivakumar et al. 2012). Also, the peaks in the wavenumber range of $2700 \mathrm{~cm}^{-1}$ to $3000 \mathrm{~cm}^{-1}$ are related to the symmetric and asymmetric tensile vibrations of $\mathrm{C}-\mathrm{H}$ bonds in organic compounds and different groups containing this bond (Petrovskii et al. 2016). Tensile and flexural vibrations related to carbonate groups $\left(\mathrm{CO}_{3}{ }^{2-}\right)$ in calcium carbonate have shown absorption peaks at $1460 \mathrm{~cm}^{-1}$ and $860 \mathrm{~cm}^{-1}$, respectively (Vagenas et al. 2003). It has also shown the flexural vibration associated with $\mathrm{C}-\mathrm{H}$ bonds and the tensile vibration associated with $\mathrm{C}-\mathrm{O}$ bonds at the $1021 \mathrm{~cm}^{-1}$ wavenumber of overlapping absorption peaks (Jung et al. 2018). In the spectrum of the pier waste sludge sample after phenol removal from petrochemical wastewater, in addition to the peaks mentioned above, the absorption peaks related to the tensile vibration of $\mathrm{N}-\mathrm{H}$ bonds in the wavenumber of about $2500 \mathrm{~cm}^{-1}$ and the tensile vibration of $\mathrm{C}-\mathrm{N}$ bond in the wavenumber of $1285 \mathrm{~cm}^{-1}$ confirms the presence of amino compounds in petrochemical wastewater that sits on the surface of the catalyst (Dias et al. 2010, Patty et al. 2017). The flexural vibration of hydroxyl bonds has also shown an absorption peak at $1682 \mathrm{~cm}^{-1}$ (Shahmoradi et al. 2020). The reduction of intensity and bandwidth related to carbonate bonds in this sample is another confirmation of the dissolution of this compound in petrochemical wastewater. In the used sample, the presence of a peak related to the flexural vibration of aromatic rings indicates the presence of phenol residues on the surface of the catalyst. Also in this sample, peaks can be observed in the wavenumber less than $500 \mathrm{~cm}^{-1}$, which is related to the tensile vibration of metal-oxygen bonds (Tavasol et al. 2020), which can be titanium, iron, and magnesium. The existence of these elements was previously confirmed by XRD. Therefore, in these results, the existence of different organic compounds such as phenol and different types of amines in petrochemical wastewater can be proven.

\subsubsection{TGAVDTG}

TGA/DTG test was used to investigate the thermal changes of the samples, and the results are shown in Fig. S4. As shown in Fig. S4, thermal decomposition occurred in the pier waste sludge thermogram at a temperature of about $760{ }^{\circ} \mathrm{C}$, which is related to the decomposition of $\mathrm{CaCO}_{3}$ and its conversion to calcium oxide and carbon dioxide ( $\mathrm{Li}$ et al. 2017). Therefore, this test also confirms the predominance of the calcium carbonate phase in pier waste sludge. In the pier waste sludge sample after removal of 
phenol from petrochemical wastewater, the lack of weight loss in the temperature of $760{ }^{\circ} \mathrm{C}$ is another confirmation of the dissolution of calcium carbonate in the wastewater solution. In used sample, weight loss occurred at temperatures between 300 and $400{ }^{\circ} \mathrm{C}$, which is related to the thermal decomposition of adsorbed organic compounds on the catalyst surface (Chavan et al. 2014). Therefore, this test, like the FTIR test, confirms the presence of significant amounts of organic compounds on the photocatalyst surface.

\subsection{Effect of wastewater $\mathrm{pH}$}

The effect of $\mathrm{pH}$ parameter on phenol removal efficiency was studied under constant operating conditions of phenol concentration of $100 \mathrm{mg} / \mathrm{L}$, PMS quantity of $100 \mathrm{mg} / \mathrm{L}$, and catalyst dose of 30 $\mathrm{mg} / \mathrm{L}$ (Fig. 2). According to the results, the highest phenol removal efficiency was obtained at $\mathrm{pH}=3$ (83.98\%) after $150 \mathrm{~min}$. With increasing $\mathrm{pH}$, the removal efficiency decreased, so $\mathrm{pH}=3$ was selected as the optimal $\mathrm{pH}$. In the process of PMS activation at the acidic $\mathrm{pH}$, the radical $\mathrm{SO}_{4}{ }^{--}$are dominant in the reaction medium which has higher oxidation power and longer half-life (Eslami et al. 2018, Khoshtinat et al. 2021). The zero electric charge point (pHpzc) of the catalyst was 8.5 and due to the positive surface charge of the catalyst at acidic $\mathrm{pH}$, it absorbs more PMS anions and increases the removal efficiency (Pang et al. 2020). Due to the radical reaction of $\mathrm{SO}_{4}{ }^{-}$with $\mathrm{OH}^{-}$in alkaline conditions and radical formation $\cdot \mathrm{OH}$ which has less oxidation potential and shorter half-life than radical, so in alkaline conditions, the removal efficiency of phenol is reduced (Liu et al. 2021). In the study of activation of persulfate with pyrite for oxidation of 2,4-dichlorophenol, the highest removal efficiency was obtained at

$\mathrm{pH}=5$ after $120 \mathrm{~min}$ (He et al. 2021). In the decomposition of 4-chlorophenol by a AOP system, the highest removal rate was obtained at $\mathrm{pH}=4$ and the lowest at $\mathrm{pH}=10$ (Eslami et al. 2018).

\subsection{Effect of catalyst mass}

Effect of catalyst dose $(0,5,10,20,30,50,80,100 \mathrm{mg} / \mathrm{L})$ on phenol removal at steady conditions $\mathrm{pH}=3$, phenol concentration of $100 \mathrm{mg} / \mathrm{L}$, and PMS quantity of $100 \mathrm{mg} / \mathrm{L}$ was examined (Fig. 3). Phenol removal efficiency increased with increasing catalyst dose up to $80 \mathrm{mg} / \mathrm{L}$ and $90.39 \%$ of phenol was removed after $150 \mathrm{~min}$. Again, with increasing the catalyst dose to $100 \mathrm{mg} / \mathrm{L}$, the removal of phenol decreased. Therefore, the catalyst dose of $80 \mathrm{mg} / \mathrm{L}$ was selected as the optimal dose. Also, the removal of phenol by PMS in the absence of a catalyst was obtained almost $8 \%$ after $150 \mathrm{~min}$. This indicates that phenol is not easily oxidized by PMS in the absence of a catalyst. Improving the phenol removal efficiency by increasing the catalyst dose to $80 \mathrm{mg} / \mathrm{L}$ is linked to the increase of active catalyst sites for PMS activation and more production of $\mathrm{SO}_{4}{ }^{--}$radicals (Huang et al. 2018, Li et al. 2020, Li et al. 2021, Wang et al. 2019). By increasing the catalyst dose to $100 \mathrm{mg} / \mathrm{L}$, the active sites of the catalyst probably decreased due to clot formation and the available surface area of the catalyst, thus reducing the phenol removal efficiency at high catalyst doses (Liu et al. 2021). The results reported by researchers such as (Liu et al. 2021) and (Saputra et al. 2020) confirm our work.

\subsection{Effect of phenol concentration}


The effect of initial contaminant concentration $(0-100 \mathrm{mg} / \mathrm{L})$ on the removal process was investigated under constant conditions of $\mathrm{pH}=3$, PMS concentration of $100 \mathrm{mg} / \mathrm{L}$, and catalyst dose of $80 \mathrm{mg} / \mathrm{L}$ (Fig. 4). With increasing the concentration of pollutants, the removal efficiency had a decreasing trend. According to the results, the removal efficiency of phenol after $20 \mathrm{~min}$ for initial concentrations of 50, 100, 150,200 , and $250 \mathrm{mg} / \mathrm{L}$ were obtained $57.38,41.36,32.82,20.28$, and $10.47 \%$, respectively. With increasing the reaction time to $150 \mathrm{~min}$, the removal efficiencies increased to $94,90.39,82.78,75.17$, and $67.56 \%$ for the abovementioned concentrations, respectively. The ratio of the number of produced $\mathrm{SO}_{4}{ }^{--}$ radicals to phenol molecules at low concentrations is higher, so the removal efficiency of phenol is higher at low concentrations (Othman et al. 2020, Zhao et al. 2020). At constant amounts of $\mathrm{SO}_{4}{ }^{-}$- radicals produced with increasing phenol concentration, the amount of exposure to $\mathrm{SO}_{4}{ }^{-\cdots}$ radicals decreases, resulting in a decrease in phenol removal (Saputra et al. 2020). In the study of phenol removal from aqueous solutions by $\mathrm{MnO}_{\mathrm{x}} / \mathrm{PMS}$ system, the highest phenol removal efficiency was $100 \%$ at $25 \mathrm{mg} / \mathrm{L}$ for $60 \mathrm{~min}$ and the lowest was $75 \%$ at $100 \mathrm{mg} / \mathrm{L}$ after $120 \mathrm{~min}$. (Saputra et al. 2013). In the decomposition of phenol from aqueous solutions by $\mathrm{MnO}_{x} / \mathrm{ACP} / \mathrm{PMS}$ system, removal of $100 \%$ phenol, at a concentration of $50 \mathrm{mg} / \mathrm{L}$ after $10 \mathrm{~min}$ and a concentration of $75 \mathrm{mg} / \mathrm{L}$ and $100 \mathrm{mg} / \mathrm{L}$ for a period of $30 \mathrm{~min}$ and $90 \mathrm{~min}$ were obtained (Saputra et al. 2020). Various researchers have stated that the rate of phenol decomposition decreases with increasing concentration and the solution to this challenge is to increase the reaction time. Comparisons of phenol removal efficiencies in different catalytic systems are given in Table 1. According to this table, the pier waste sludge catalyst/PMS system, in comparison with other processes, has a good efficiency for removing phenol from petrochemical wastewater.

Table 1. Comparison of phenol removal efficiency in different catalytic systems.

\begin{tabular}{|c|c|c|c|}
\hline Studied system & $\begin{array}{l}\text { Initial content of phenol } \\
(\mathrm{mg} / \mathrm{L})\end{array}$ & $\begin{array}{l}\text { Removal efficiency } \\
(\%)\end{array}$ & Reference \\
\hline Biochar-La/US/PS & 42.25 & $>99$ & (Razmi et al. 2019) \\
\hline $\mathrm{Mn}_{2} \mathrm{O}_{3} / \mathrm{PMS}$ & 50 & 98 & (Saputra et al. 2013) \\
\hline UV/PS & 200 & $\approx 91$ & $\begin{array}{l}\text { (Seid-Mohammadi et a } \\
\text { 2016) }\end{array}$ \\
\hline $\begin{array}{l}\mathrm{Cu}- \\
\mathrm{Co}_{3} \mathrm{O}_{4} @ \mathrm{MnO}_{2} / \mathrm{PMS}\end{array}$ & 30 & 100 & (Khan et al. 2017) \\
\hline $\mathrm{Ag} / \mathrm{ZnO} / \mathrm{PMS} / \mathrm{Vis}$ & 30 & $\approx 100$ & (Truong et al. 2021) \\
\hline MnOx/ACP/PMS & 75 & 100 & (Saputra et al. 2020) \\
\hline US/PS & 17 & 90.92 & (Moradnia et al. 2021) \\
\hline $\begin{array}{l}\text { Pier waste } \\
\text { sludge /PMS }\end{array}$ & 50 & 94 & This work \\
\hline
\end{tabular}

\subsection{Effect of PMS dose}


The effect of PMS concentration $(50-50 \mathrm{mg} / \mathrm{L})$ on the phenol removal process was evaluated under operating conditions of $\mathrm{pH}=3$, phenol concentration of $100 \mathrm{mg} / \mathrm{L}$, and catalyst dose of $80 \mathrm{mg} / \mathrm{L}$ (Fig. 5). According to the results, increasing the PMS concentration to $150 \mathrm{mg} / \mathrm{L}$ increased the phenol removal efficiency and $92.98 \%$ of the contaminant was removed from the wastewater after $150 \mathrm{~min}$. By increasing the concentration of PMS to $250 \mathrm{mg} / \mathrm{L}$, a decreasing trend of phenol removal from wastewater was observed and $87.56 \%$ of the contaminant was removed. Therefore, a concentration of $150 \mathrm{mg} / \mathrm{L}$ was considered as the optimal concentration. Phenol oxidation in the absence of PMS indicated that approximately $14 \%$ of phenol was removed after $150 \mathrm{~min}$ and the removal of the contaminant was significantly reduced in the absence of PMS, and the major removal mechanism in the absence of PMS was probably attributed to adsorption. Increasing the PMS concentration to $150 \mathrm{mg} / \mathrm{L}$ increased the phenol removal efficiency due to the production of more free radicals (Truong et al. 2021). Probably at concentrations higher than $150 \mathrm{mg} / \mathrm{L} \mathrm{SO}_{4}{ }^{*-}$ radicals have a self-scavenger role. It also reacts with $\mathrm{SO}_{4}{ }^{-{ }^{-}}$ radicals at concentrations of PMS above $150 \mathrm{mg} / \mathrm{L}$ excess $\mathrm{HSO}_{5}{ }^{-}$and leads to weak $\mathrm{SO}_{5}{ }^{-{ }^{-} \text {radical }}$ production (Eqs. (5-8)) (Ghanbari et al. 2020, Hu et al. 2018, Liu et al. 2021).

$$
\begin{aligned}
& \mathrm{HSO}_{5}{ }^{-}+\mathrm{SO}_{4}{ }^{--} \rightarrow \mathrm{SO}_{5}{ }^{--}+\mathrm{H}^{+}+\mathrm{SO}_{4}{ }^{2-} \\
& \cdot \mathrm{OH}+\mathrm{SO}_{4}{ }^{--} \rightarrow \mathrm{HSO}_{5}{ }^{-} \\
& \mathrm{SO}_{4}{ }^{--}+\mathrm{SO}_{4}{ }^{--} \rightarrow \mathrm{S}_{2} \mathrm{O}_{8}{ }^{2-} \\
& \mathrm{HSO}_{5}{ }^{-}+\cdot \mathrm{OH} \rightarrow \mathrm{SO}_{5}{ }^{--}+\mathrm{OH}^{-}
\end{aligned}
$$

\subsection{Phenol removal kinetics}

Phenol removal kinetics were evaluated at $\mathrm{pH}=3$, catalyst dose $80 \mathrm{mg} / \mathrm{L}$, PMS concentration $150 \mathrm{mg} / \mathrm{L}$, phenol concentration (50-250 mg/L), and contact time (20-150 min) (Fig. 6). According to the results, the highest rate of phenol degradation was achieved at an initial concentration of $50 \mathrm{mg} / \mathrm{L}$ with the rate of $0.0144 \mathrm{~min}^{-1}$. The correlation coefficient $\left(R^{2}\right)$ for all concentrations was higher than 0.94 , which indicates that in the studied system, the data suitably fit the first-order kinetics. Also, with increasing phenol concentration, the reaction proceeded at a slower rate (Saputra et al. 2020). The results of studies by other researchers for phenol degradation followed first-order kinetics (Li et al. 2020, Othman et al. 2020, Saputra et al. 2020, Vaiano et al. 2018).

\subsection{Reuse of the studied catalyst}

Reuse of pier waste sludge catalyst was evaluated in 5 cycles under optimal conditions of $\mathrm{pH}=3$, catalyst dose $80 \mathrm{mg} / \mathrm{L}$, phenol concentration $50 \mathrm{mg} / \mathrm{L}$, PMS concentration $150 \mathrm{mg} / \mathrm{L}$, and reaction time $150 \mathrm{~min}$ (Fig. 7). The fresh catalyst removed approximately $94 \%$ of the phenol. During the first, second, and third cycles, $83.5 \%, 71.9 \%$, and $64.2 \%$ of the phenol were removed, respectively. However, in the fifth cycle, the catalytic activity of the pier waste sludge decreased and approximately $42 \%$ of phenol was removed. We 
hypothesize that this decrease in efficiency is related to catalyst leaching and leakage of active catalyst components into the liquid phase, as well as changes in the structure and deposition of by-products at the catalyst sludge catalyst surface (Khan et al. 2017, Saputra et al. 2013). The catalytic activity of $\mathrm{Mn}_{2} \mathrm{O}_{3}$ in the second cycle was reduced to $27 \%$ for phenol decomposition (Saputra et al. 2013). Phenol removal efficiency by $\mathrm{MnO}_{x} / \mathrm{ACP}$ catalyst in the first cycle decreased to $38 \%$ after 90 min (Saputra et al. 2020). Therefore, it can be concluded that the pier sludge is a suitable catalyst with optimal activity and stability.

\subsection{Energy consumption by the system}

To select advanced oxidation systems to remove pollutants, special attention is paid to the consumption of electrical energy (Moussavi \&Rezaei 2017). Electrical energy consumption (EEC, kw.h/m $\mathrm{m}^{3}$ ) in the pier waste sludge catalyst/PMS system at $\mathrm{pH}=3$, catalyst dose $80 \mathrm{mg} / \mathrm{L}$, PMS concentration $150 \mathrm{mg} / \mathrm{L}$, phenol concentration $50 \mathrm{mg} / \mathrm{L}$, and reaction time 100 min was quantified according to the following formula (Bessegato et al. 2018, Dhaka et al. 2018, Tavasol et al. 2021).

$$
\mathrm{EEC}=\frac{\mathrm{P} * \mathrm{t} * 1000}{\mathrm{~V} * 60 * \log \left(\frac{\text { Inlet phenol }}{\text { Outlet phenol }}\right)}
$$

In this formula, $t$ denotes the time of reaction ( $\min ), \mathrm{P}$ implies the input power $(\mathrm{kW}), \mathrm{V}$ denotes the treated volume of petrochemical wastewater $(L)$.

The amount of EEC for the investigated system was attained $77.69 \mathrm{kw} \cdot \mathrm{h} / \mathrm{m}^{3}$. In the UV/PMS oxidation system, the EEC level was $143.7 \mathrm{kw} . \mathrm{h} / \mathrm{m}^{3}$ (Dhaka et al. 2018). The quantity of EEC to remove phenol from aqueous solutions by UV process was obtained $400 \mathrm{kw} . \mathrm{h} / \mathrm{m}^{3}$ (Yazdanbakhsh et al. 2020). Therefore, due to less energy consumption in this study than published works, the pier waste sludge catalyst/PMS system can be considered as a suitable process for phenol remediation purposes.

\section{Conclusion}

This study reported the performance of a catalyst extracted from pier waste sludge in combination with PMS to remove phenol from petrochemical wastewater. In this study, the effects of parameters of $\mathrm{pH}$ (39), catalyst dose (0-100 mg/L), PMS concentration (0-250 mg/L), and initial phenol concentration (50-50 $\mathrm{mg} / \mathrm{L}$ ) on phenol decontamination were tested. According to the results in low phenol concentrations (50 $\mathrm{mg} / \mathrm{L}$ ), catalyst dose of $80 \mathrm{mg} / \mathrm{L}$, and PMS concentration of $150 \mathrm{mg} / \mathrm{L}$, the highest phenol removal efficiency from real wastewater (94\%) was achieved after $150 \mathrm{~min}$. The highest rate of phenol degradation was obtained in the initial concentration of $50 \mathrm{mg} / \mathrm{L}$ at the rate of $0.0144 \mathrm{~min}^{-1}$. The correlation coefficient $\left(R^{2}\right)$ for all concentrations was $>0.94$, which indicates that in the studied system, the data abbey the first-order kinetics. After the fifth cycle. The catalyst stability was reduced to less than $50 \%$. According to the results, the energy consumption in the pier waste sludge catalyst/PMS system for 
phenol removal was $77.69 \mathrm{kw} \cdot \mathrm{h} / \mathrm{m}^{3}$. Therefore, the pier waste sludge catalyst/PMS system is an excellent strategy to remove phenol from real wastewater.

\section{Declarations}

\section{Author contribution}

F. Khoshtinat: Formal analysis, Methodology, Writing-original draft. T. Tabatabaie: Supervision, Methodology. B. Ramavandi: Supervision, Conceptualization, Writing- review\& editing. S. Hashemi: Conceptualization.

\section{Funding}

This research did not receive any specific grant from funding agencies in the public, commercial, or notfor-profit sectors.

\section{Availability of data and materials}

The datasets used in this study are available from the corresponding author on reasonable request.

\section{Declarations}

Ethical approval not applicable.

\section{Ethics approval and consent to participate}

Not applicable

\section{Consent to publish}

All authors declare they have given consent to publish this article.

\section{Competing interests}

The authors declare no competing interests.

\section{References}

Al-Huwaidi JS, Al-Obaidi MA, Jarullah AT, Kara-Zaïtri C, Mujtaba IM (2021): Modeling and simulation of a hybrid system of trickle bed reactor and multistage reverse osmosis process for the removal of phenol from wastewater. Computers \& Chemical Engineering 153, 107452

Al Bsoul A, Hailat M, Abdelhay A, Tawalbeh M, Al-Othman A, Al-Taani AA (2021): Efficient removal of phenol compounds from water environment using Ziziphus leaves adsorbent. Science of the Total Environment 761, 143229 
Ali JK, Chabib CM, Abi Jaoude M, Alhseinat E, Teotia S, Patole S, Anjum DH, Qattan I (2021): Enhanced removal of aqueous phenol with polyimide ultrafiltration membranes embedded with deep eutectic solvent-coated nanosilica. Chemical Engineering Journal 408, 128017

Bessegato GG, De Souza JC, Cardoso JC, Zanoni MVB (2018): Assessment of several advanced oxidation processes applied in the treatment of environmental concern constituents from a real hair dye wastewater. Journal of Environmental Chemical Engineering 6, 2794-2802

Bin-Dahman OA, Saleh TA (2020): Synthesis of carbon nanotubes grafted with PEG and its efficiency for the removal of phenol from industrial wastewater. Environmental Nanotechnology, Monitoring \& Management 13, 100286

Camacho MAN, López AIG, Martinez-Ferez A, Ochando-Pulido JM (2021): Increasing large-scale feasibility of two-phase olive-oil washing wastewater treatment and phenolic fraction recovery with novel ion exchange resins. Chemical Engineering and Processing-Process Intensification 164, 108416

Chavan SM, Shearer GC, Svelle S, Olsbye U, Bonino F, Ethiraj J, Lillerud KP, Bordiga S (2014): Synthesis and characterization of amine-functionalized mixed-ligand metal-organic frameworks of UiO-66 topology. Inorganic chemistry 53, 9509-9515

Cui Y-H, Lv X-D, Lei J-X, Liu Z-Q (2017): Synergistic effect of cathode/peroxymonosulfate/Fe3+ on phenol degradation. Electrochimica Acta 245, 201-210

Dhaka S, Kumar R, Lee S-h, Kurade MB, Jeon B-H (2018): Degradation of ethyl paraben in aqueous medium using advanced oxidation processes: efficiency evaluation of UV-C supported oxidants. Journal of cleaner production $180,505-513$

Dias RCM, Góes AM, Serakides R, Ayres E, Oréfice RL (2010): Porous biodegradable polyurethane nanocomposites: preparation, characterization, and biocompatibility tests. Materials Research 13, 211218

Ding M, Ao W, Xu H, Chen W, Tao L, Shen Z, Liu H, Lu C, Xie Z (2021): Facile construction of dual heterojunctionCoO@TiO2/MXene hybrid with efficient and stable catalytic activity for phenol degradation with peroxymonosulfate under visible light irradiation. Journal of Hazardous Materials 420, 126686

Eslami A, Hashemi M, Ghanbari F (2018): Degradation of 4-chlorophenol using catalyzed peroxymonosulfate with nano-MnO2/UV irradiation: Toxicity assessment and evaluation for industrial wastewater treatment. Journal of Cleaner Production 195, 1389-1397

Ganguly P, Sarkhel R, Bhattacharya S, Das P, Saha A, Bhowal A (2020): Integral approach of treatment of phenolic wastewater using nano-metal coated graphene oxide in combination with advanced oxidation. Surfaces and Interfaces 21, 100660 
Gao Q, Cui Y, Wang S, Liu B, Liu C (2021): Efficient activation of peroxymonosulfate by Co-doped mesoporous $\mathrm{CeO} 2$ nanorods as a heterogeneous catalyst for phenol oxidation. Environmental Science and Pollution Research 28, 27852-27863

Ghanbari F, Khatebasreh M, Mahdavianpour M, Lin K-YA (2020): Oxidative removal of benzotriazole using peroxymonosulfate/ozone/ultrasound: Synergy, optimization, degradation intermediates and utilizing for real wastewater. Chemosphere 244, 125326

Hajipour F, Asad S, Amoozegar MA, Javidparvar AA, Tang J, Zhong H, Khajeh K (2021): Developing a Fluorescent Hybrid Nanobiosensor Based on Quantum Dots and Azoreductase Enzyme for Methyl Red Monitoring. Iranian Biomedical Journal 25, 8

He P, Zhu J, Chen Y, Chen F, Zhu J, Liu M, Zhang K, Gan M (2021): Pyrite-activated persulfate for simultaneous 2, 4-DCP oxidation and Cr (VI) reduction. Chemical Engineering Journal 406, 126758

Honarmandrad Z, Javid N, Malakootian M (2021): Removal efficiency of phenol by ozonation process with calcium peroxide from aqueous solutions. Applied Water Science 11, 1-9

Hu L, Zhang G, Liu M, Wang Q, Wang P (2018): Optimization of the catalytic activity of a ZnCo204 catalyst in peroxymonosulfate activation for bisphenol A removal using response surface methodology. Chemosphere 212, 152-161

Hu L, Zhang G, Liu M, Wang Q, Dong S, Wang P (2019): Application of nickel foam-supported Co304$\mathrm{Bi} 203$ as a heterogeneous catalyst for BPA removal by peroxymonosulfate activation. Science of the total environment 647, 352-361

Huang T, Zhang K, Qian Y, Fang C, Chen J (2018): Ultrasound enhanced activation of peroxydisulfate by activated carbon fiber for decolorization of azo dye. Environmental Science and Pollution Research 25, 14407-14414

Jung MR, Horgen FD, Orski SV, Rodriguez V, Beers KL, Balazs GH, Jones TT, Work TM, Brignac KC, Royer S-J (2018): Validation of ATR FT-IR to identify polymers of plastic marine debris, including those ingested by marine organisms. Marine Pollution Bulletin 127, 704-716

Kanimozhi K, Sankara P, Shyamala R, Jian L (2014): Effect of Sodium Chloride Concentration on the Corrosion of Carbon Steels and Stainless Steels in $\mathrm{CO} 2$ Environment at Atmospheric Pressure under Turbulent Flow Condition, CORROSION 2014. OnePetro

Khan A, Liao Z, Liu Y, Jawad A, Ifthikar J, Chen Z (2017): Synergistic degradation of phenols using peroxymonosulfate activated by CuO-Co304@ MnO2 nanocatalyst. Journal of hazardous materials 329, 262-271

Khoshtinat F, Tabatabaie T, Ramavandi B, Hashemi S (2021): Phenol removal kinetics from synthetic wastewater by activation of persulfate using a catalyst generated from shipping ports sludge. 
Li L, Wu H, Chen H, Zhang J, Xu X, Wang S, Wang S, Sun H (2020): Heterogeneous activation of peroxymonosulfate by hierarchically porous cobalt/iron bimetallic oxide nanosheets for degradation of phenol solutions. Chemosphere 256, 127160

Li X-G, Lv Y, Ma B-G, Wang W-Q, Jian S-W (2017): Decomposition kinetic characteristics of calcium carbonate containing organic acids by TGA. Arabian Journal of Chemistry 10, S2534-S2538

Li X, Ye L, Ye Z, Xie S, Qiu Y, Liao F, Lin C, Liu M (2021): N, P co-doped core/shell porous carbon as a highly efficient peroxymonosulfate activator for phenol degradation. Separation and Purification Technology 276, 119286

Liu X, Zhou J, Liu D, Li L, Liu W, Liu S, Feng C (2021): Construction of Z-scheme CuFe204/MnO2 photocatalyst and activating peroxymonosulfate for phenol degradation: Synergistic effect, degradation pathways, and mechanism. Environmental Research 200, 111736

Mady AH, Baynosa ML, Tuma D, Shim J-J (2019): Heterogeneous activation of peroxymonosulfate by a novel magnetic 3D y-MnO2@ ZnFe204/rGO nanohybrid as a robust catalyst for phenol degradation. Applied Catalysis B: Environmental 244, 946-956

Mahieux P-Y, Aubert J-E, Cyr M, Coutand M, Husson B (2010): Quantitative mineralogical composition of complex mineral wastes-Contribution of the Rietveld method. Waste Management 30, 378-388

Moradnia M, Noorisepehr M, Salari M, Darvishmotevalli M (2021): Optimization of 2-Chlorophenol Removal Using Ultrasound/Persulfate: Prediction by RSM Method, Biodegradability Improvement of Petrochemical Refinery Wastewater. Arabian Journal for Science and Engineering, 1-9

Moussavi G, Rezaei M (2017): Exploring the advanced oxidation/reduction processes in the VUV photoreactor for dechlorination and mineralization of trichloroacetic acid: parametric experiments, degradation pathway and bioassessment. Chemical Engineering Journal 328, 331-342

Nirmala G, Murugesan T, Rambabu K, Sathiyanarayanan K, Show PL (2021): Adsorptive removal of phenol using banyan root activated carbon. Chemical Engineering Communications 208, 831-842

Othman I, Zain JH, Haija MA, Banat F (2020): Catalytic activation of peroxymonosulfate using CeVO4 for phenol degradation: an insight into the reaction pathway. Applied Catalysis B: Environmental 266, 118601

Pandian AMK, Rajasimman M, Rajamohan N, Varjani S, Karthikeyan C (2021): Anaerobic mixed consortium (AMC) mediated enhanced biosynthesis of silver nano particles (AgNPs) and its application for the removal of phenol. Journal of Hazardous Materials 416, 125717 
Pang Y, Zhou Y, Luo K, Zhang Z, Yue R, Li X, Lei M (2020): Activation of persulfate by stability-enhanced magnetic graphene oxide for the removal of 2, 4-dichlorophenol. Science of the Total Environment 707, 135656

Patty DJ, Loupatty G, Sopalauw F (2017): Interpretation FTIR spectrum of seawater and sediment in the Ambon Bay (TAD), AIP Conference Proceedings. AIP Publishing LLC, pp. 060005

Petrovskii S, Stepanova O, Vorobyeva S, Pogodaeva T, Fedotov A (2016): The use of FTIR methods for rapid determination of contents of mineral and biogenic components in lake bottom sediments, based on studying of East Siberian lakes. Environmental Earth Sciences 75, 226

Razmi R, Ramavandi B, Ardjmand M, Heydarinasab A (2019): Efficient phenol removal from petrochemical wastewater using biochar-La/ultrasonic/persulphate system: characteristics, reusability, and kinetic study. Environmental technology 40, 822-834

Rivas F, Gimeno O, Borallho T (2012): Aqueous pharmaceutical compounds removal by potassium monopersulfate. Uncatalyzed and catalyzed semicontinuous experiments. Chemical engineering journal $192,326-333$

Saputra E, Muhammad S, Sun H, Ang H-M, Tadé MO, Wang S (2013): Manganese oxides at different oxidation states for heterogeneous activation of peroxymonosulfate for phenol degradation in aqueous solutions. Applied Catalysis B: Environmental 142, 729-735

Saputra E, Pinem J, Budihardjo M, Utama P, Wang S (2020): Carbon-supported manganese for heterogeneous activation of peroxymonosulfate for the decomposition of phenol in aqueous solutions. Materials Today Chemistry 16, 100268

Seid-Mohammadi A, Asgari G, Poormohammadi A, Ahmadian M, Rezaeivahidian H (2016): Removal of phenol at high concentrations using UV/Persulfate from saline wastewater. Desalination and Water Treatment 57, 19988-19995

Shahmoradi A, Talebibahmanbigloo N, Javidparvar A, Bahlakeh G, Ramezanzadeh B (2020): Studying the adsorption/inhibition impact of the cellulose and lignin compounds extracted from agricultural waste on the mild steel corrosion in $\mathrm{HCl}$ solution. Journal of Molecular Liquids 304, 112751

Sivakumar S, Ravisankar R, Raghu Y, Chandrasekaran A, Chandramohan J (2012): FTIR spectroscopic studies on coastal sediment samples from Cuddalore District, Tamilnadu, India. Indian Journal of Advances in Chemical Science 1, 40-46

Tavasol F, Tabatabaie T, Ramavandi B, Amiri F (2020): Design a new photocatalyst of sea sediment/titanate to remove cephalexin antibiotic from aqueous media in the presence of sonication/ultraviolet/hydrogen peroxide: Pathway and mechanism for degradation. Ultrasonics sonochemistry 65,105062 
Tavasol F, Tabatabaie T, Ramavandi B, Amiri F (2021): Photocatalyst production from wasted sediment and quality improvement with titanium dioxide to remove cephalexin in the presence of hydrogen peroxide and ultrasonic waves: A cost-effective technique. Chemosphere 284, 131337

Truong TK, Nguyen TQ, La HPP, Le HV, Van Man T, Cao TM, Van Pham V (2021): Insight into the degradation of $\mathrm{p}$-nitrophenol by visible-light-induced activation of peroxymonosulfate over $\mathrm{Ag} / \mathrm{ZnO}$ heterojunction. Chemosphere 268, 129291

Vagenas N, Gatsouli A, Kontoyannis C (2003): Quantitative analysis of synthetic calcium carbonate polymorphs using FT-IR spectroscopy. Talanta 59, 831-836

Vaiano V, Matarangolo M, Murcia J, Rojas H, Navío JA, Hidalgo M (2018): Enhanced photocatalytic removal of phenol from aqueous solutions using $\mathrm{ZnO}$ modified with Ag. Applied Catalysis B:

Environmental 225, 197-206

Wang J, Xie T, Han G, Zhu Q, Wang Y, Peng Y, Liu S, Yao Z (2021): SiO2 mediated templating synthesis of $\mathrm{Y}$-Fe203/MnO2 as peroxymonosulfate activator for enhanced phenol degradation dominated by singlet oxygen. Applied Surface Science 560, 149984

Wang Q, Li Y, Shen Z, Liu X, Jiang C (2019): Facile synthesis of three-dimensional Mn304 hierarchical microstructures for efficient catalytic phenol oxidation with peroxymonosulfate. Applied Surface Science 495,143568

Yazdanbakhsh A, Aliyari A, Sheikhmohammadi A, Aghayani E (2020): Application of the enhanced sonophoto-Fenton-like process in the presence of persulfate for the simultaneous removal of chromium and phenol from the aqueous solution. Journal of Water Process Engineering 34, 101080

Zhang H, Tang L, Wang J, Yu J, Feng H, Lu Y, Chen Y, Liu Y, Wang J, Xie Q (2020): Enhanced surface activation process of persulfate by modified bagasse biochar for degradation of phenol in water and soil: Active sites and electron transfer mechanism. Colloids and Surfaces A: Physicochemical and Engineering Aspects 599, 124904

Zhao C, Zhong S, Li C, Zhou H, Zhang S (2020): Property and mechanism of phenol degradation by biochar activated persulfate. Journal of Materials Research and Technology 9, 601-609

\section{Figures}




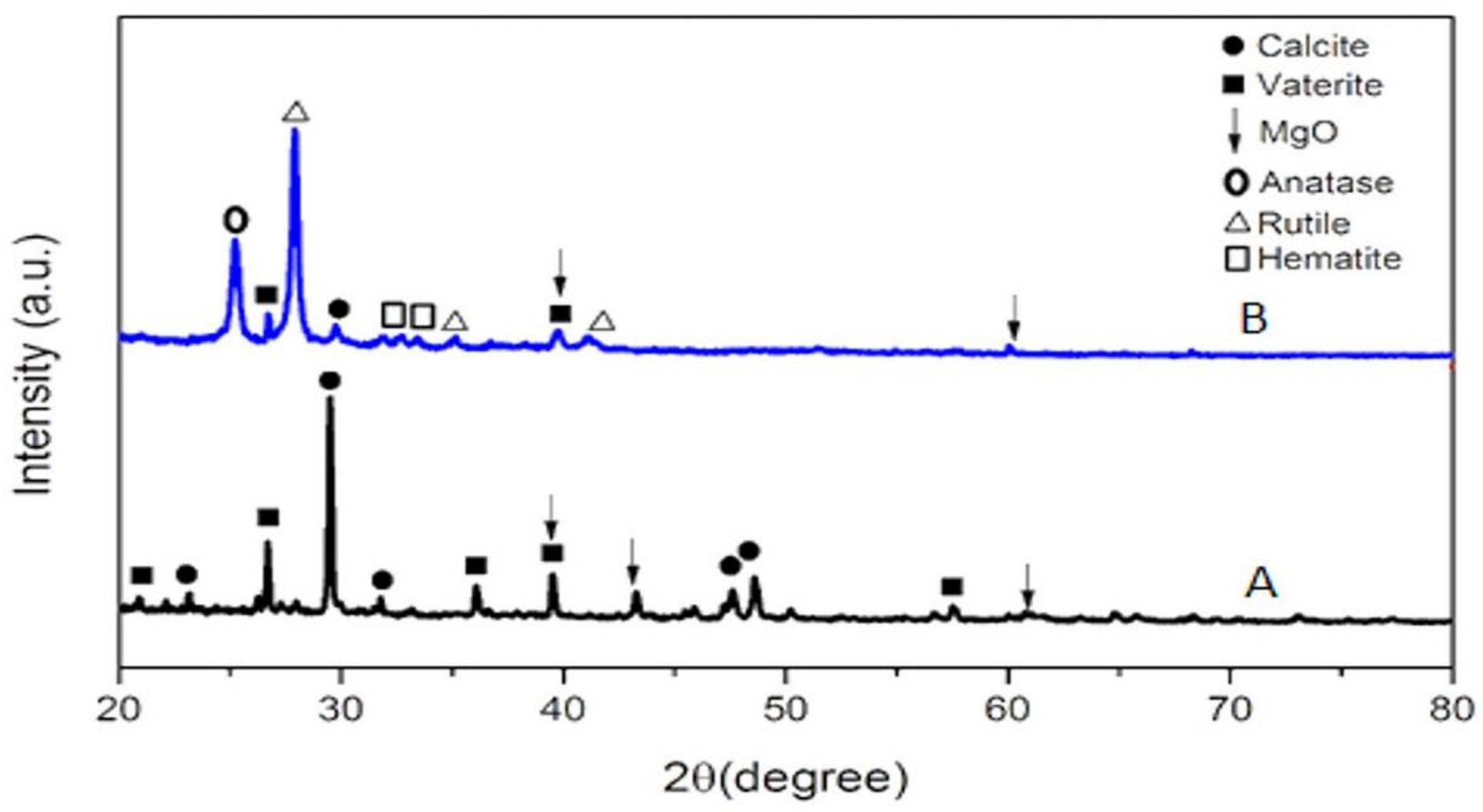

Figure 1

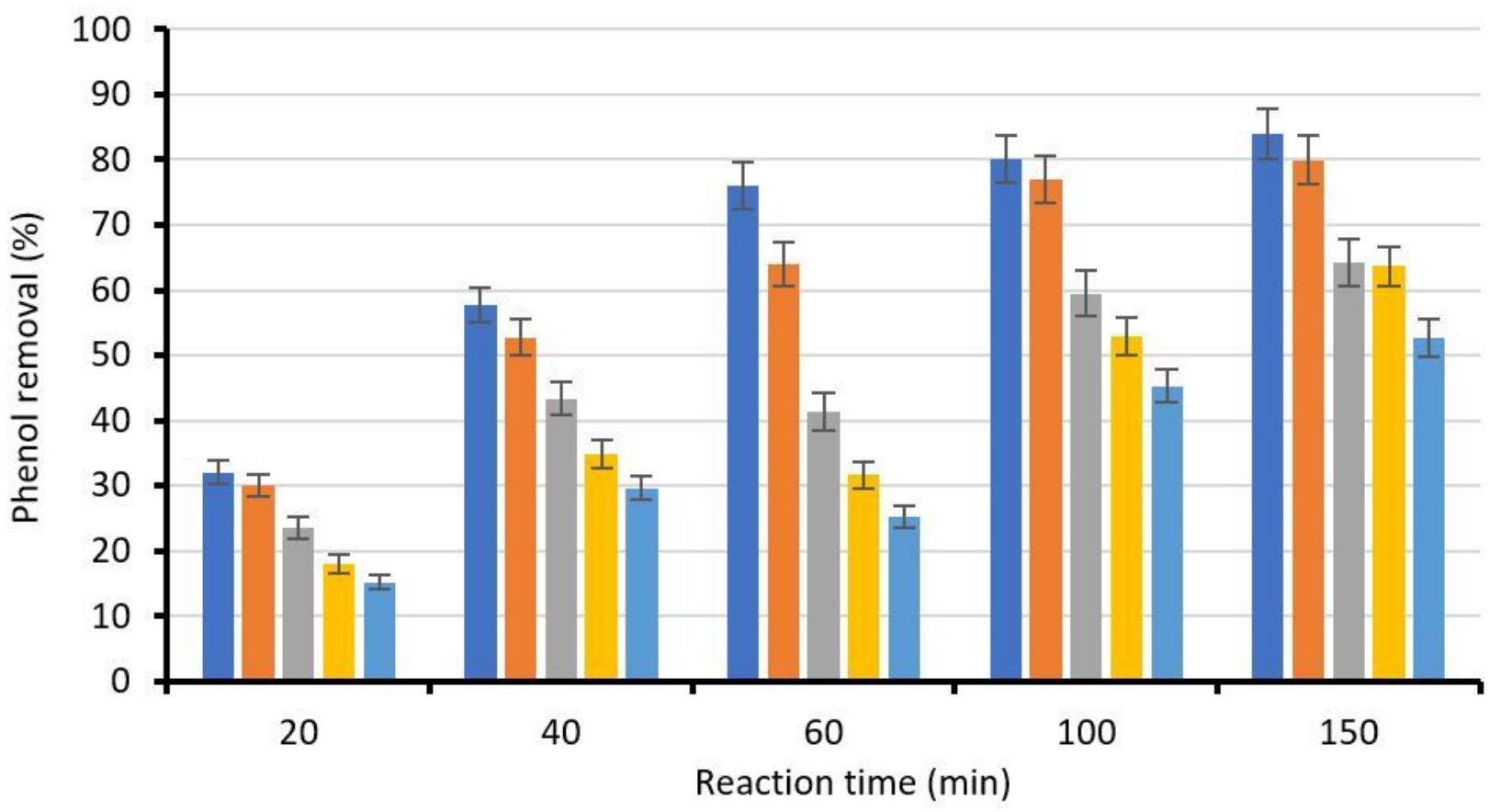

pH: 3

$\mathrm{pH}: 5$

$\mathrm{pH}: 7$

$\mathrm{pH}: 8$

aH: 9

Figure 2

Effect of wastewater pH ([Phenol]: $100 \mathrm{mg} / \mathrm{L}$; [PMS]: $100 \mathrm{mg} / \mathrm{L}$; [Catalyst]: $30 \mathrm{mg} / \mathrm{L}$ ). 


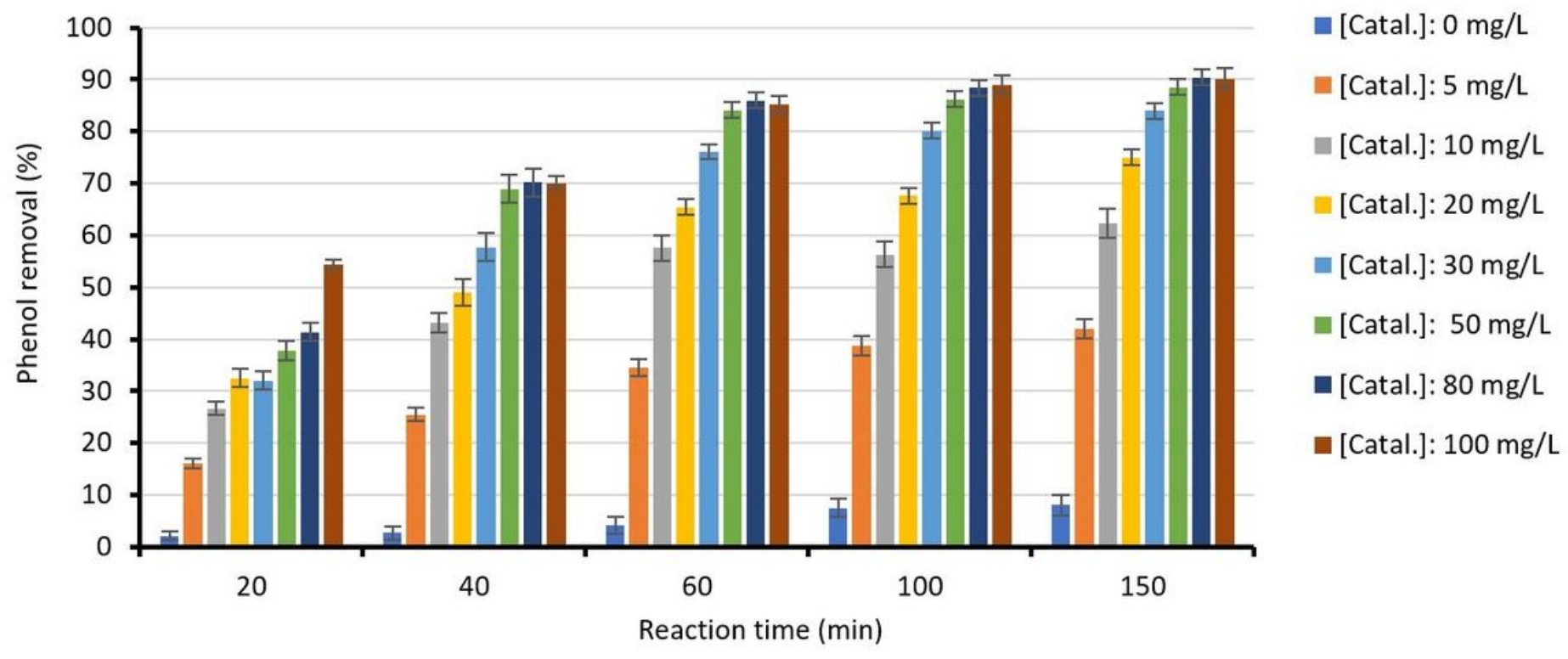

Figure 3

Effect of catalyst mass (pH: 3; [PMS]: 100 mg/L; [Phenol]: 100 mg/L).

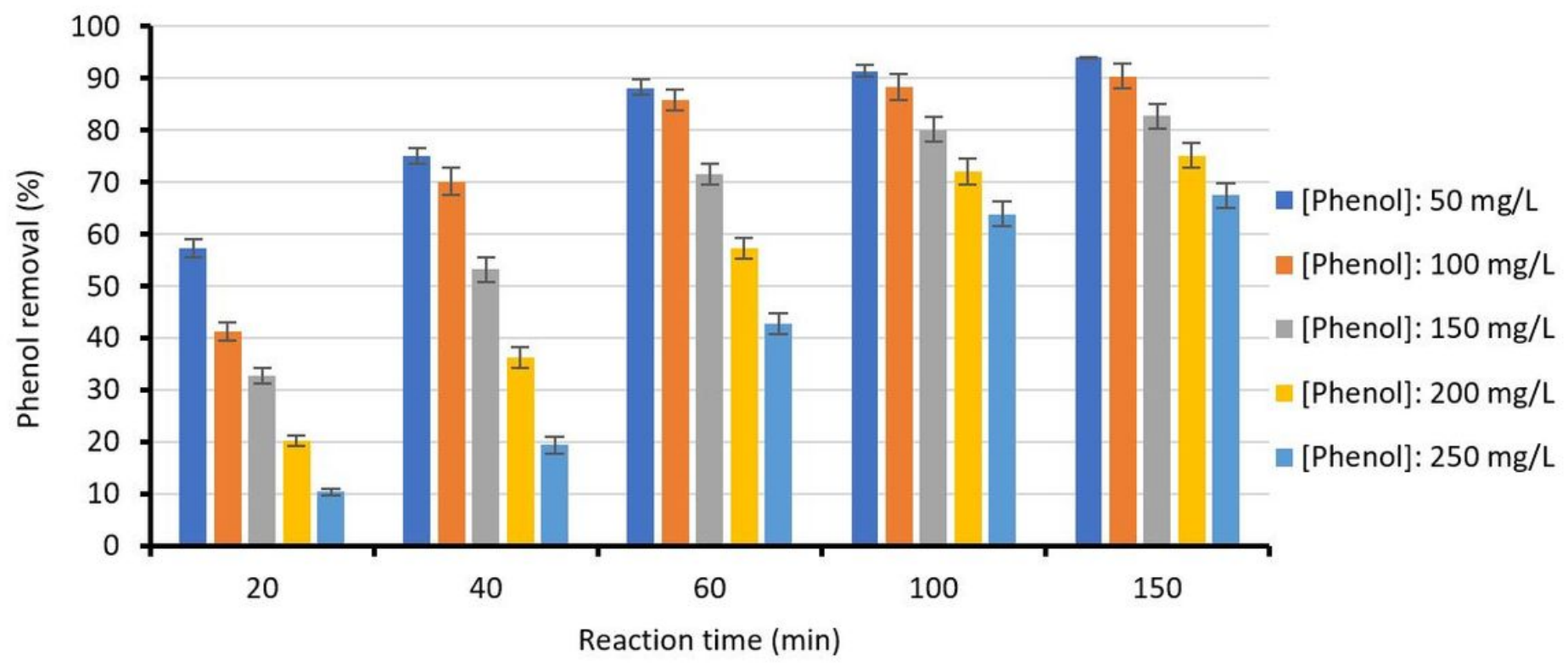

Figure 4

Effect of phenol concentration (pH: 3; [PMS]: $100 \mathrm{mg} / \mathrm{L}$; [Catalyst]: $80 \mathrm{mg} / \mathrm{L}$ ). 


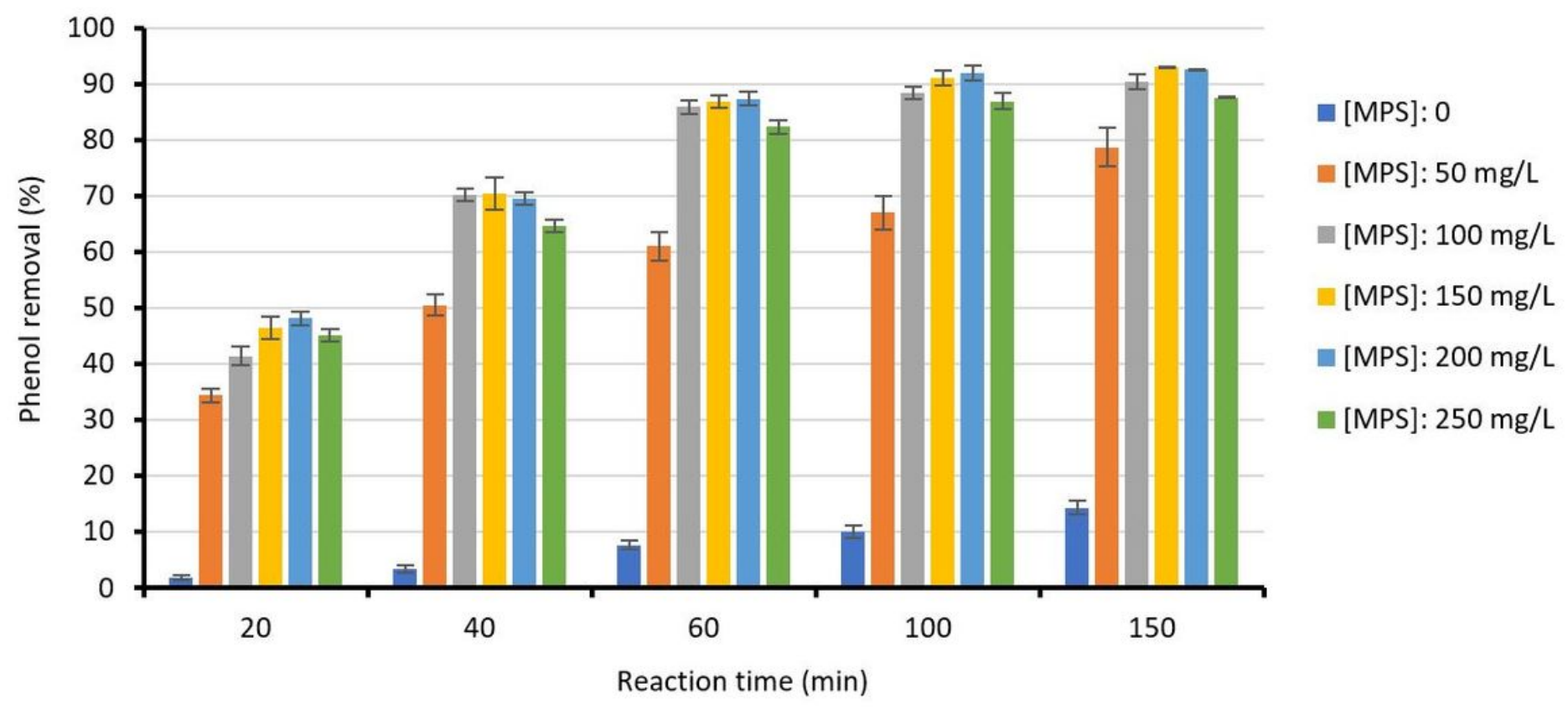

Figure 5

Effect of PMS dose (pH: 3; [Phenol]: 100 mg/L; [Catalyst]: 80 mg/L).

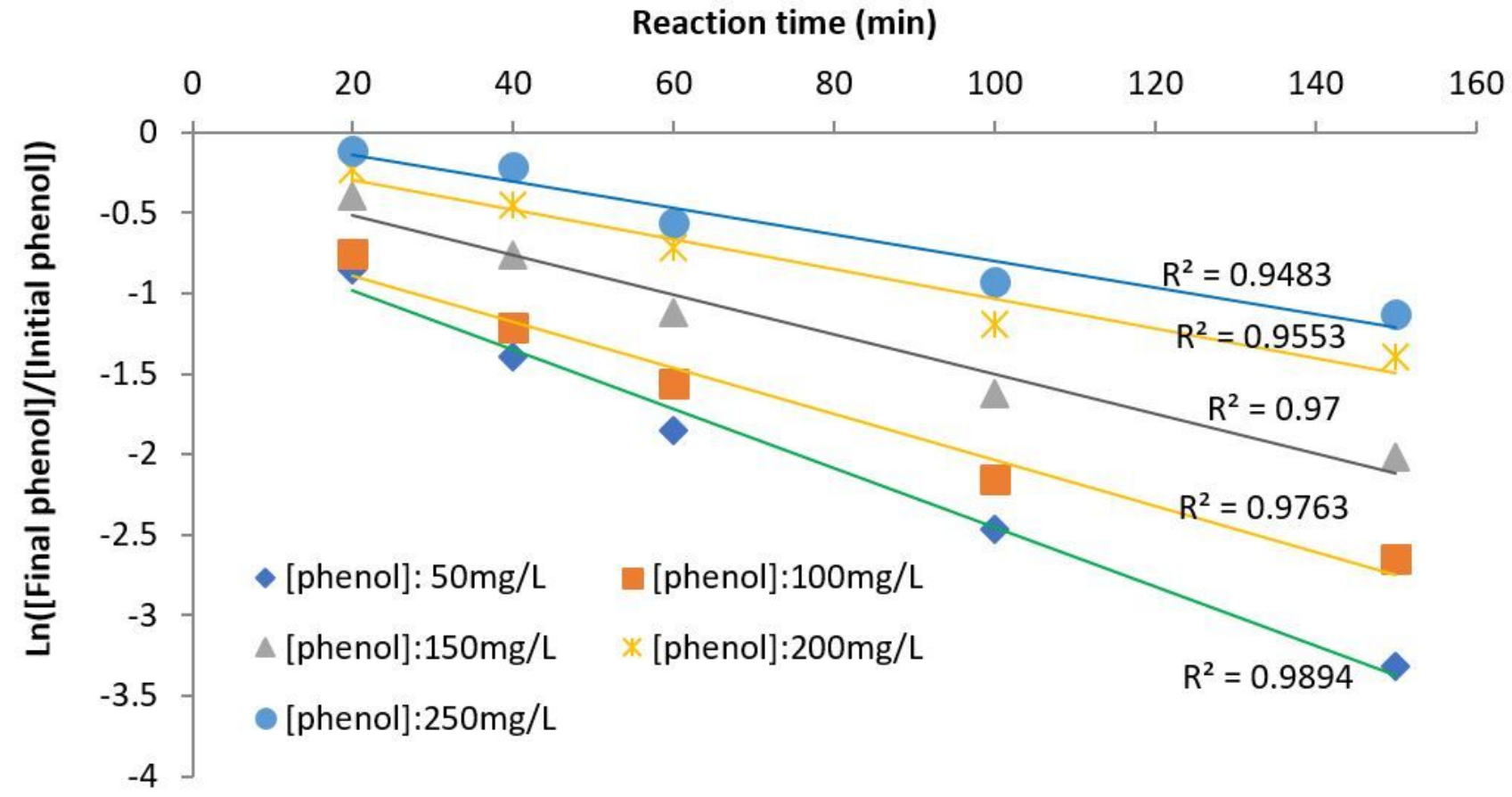

Figure 6

First-order kinetics for phenol degradation in the pier waste sludge catalyst/PMS system (pH: 3; [Catalyst]: $80 \mathrm{mg} / \mathrm{L}$; [PMS]: $150 \mathrm{mg} / \mathrm{L}$ ). 


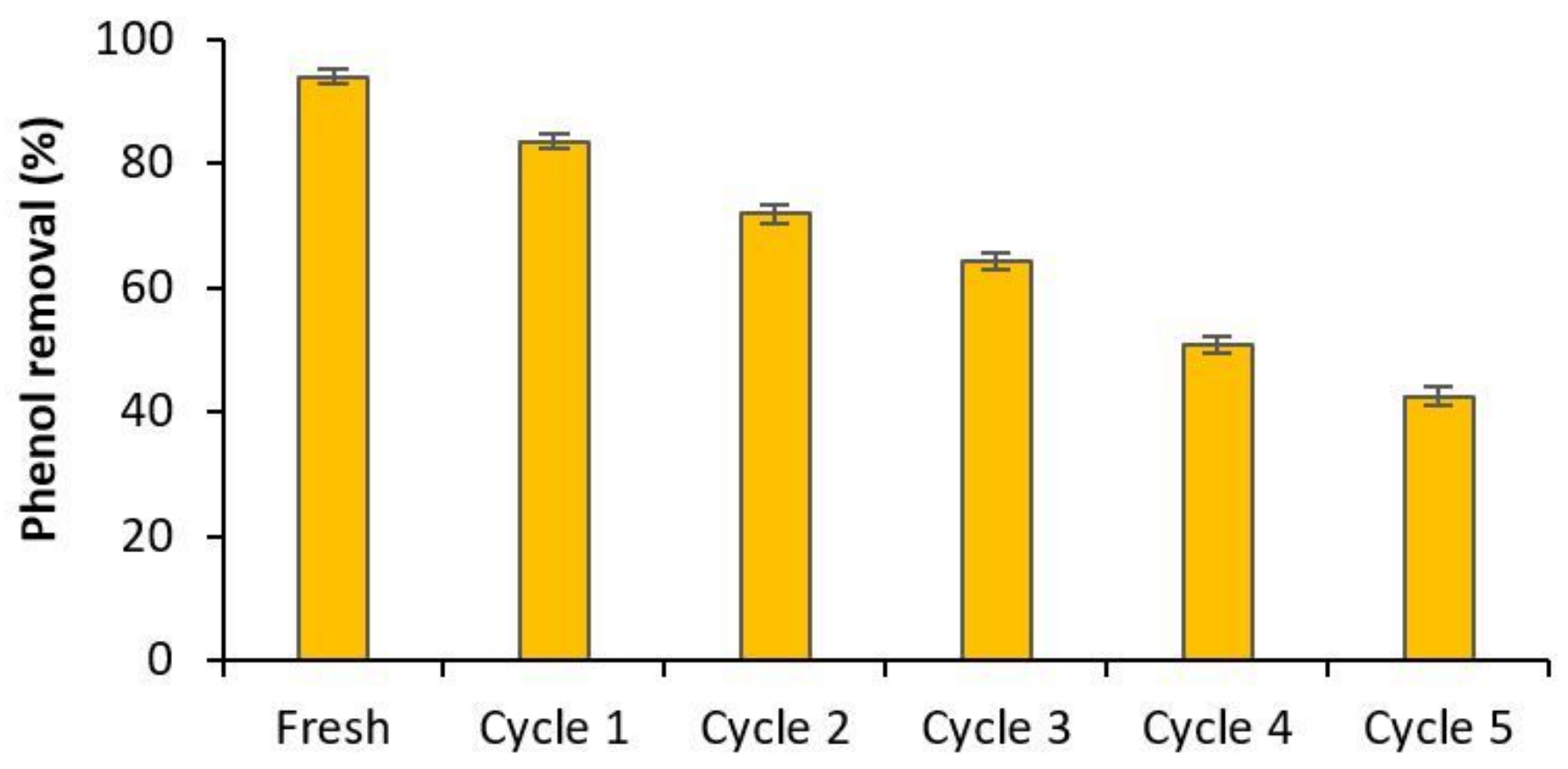

Cycles of use

Figure 7

Reuse the catalyst to remove phenol from the petrochemical wastewater $(\mathrm{pH}: 3$; [Catalyst]: $80 \mathrm{mg} / \mathrm{L}$; [Phenol]: $50 \mathrm{mg} / \mathrm{L}$; [PMS]: $150 \mathrm{mg} / \mathrm{L}$; [Reaction time]: $150 \mathrm{~min}$ ).

\section{Supplementary Files}

This is a list of supplementary files associated with this preprint. Click to download.

- Supplementaryinfo.docx 